\title{
Cardiac implantable electronic device surgery with interruption of warfarin forgoing post-operative bridging therapy in patients with moderate or high thromboembolic risks
}

\author{
Andrew Kei-Yan $\mathrm{Ng}^{1 *}$, Pauline Yeung $\mathrm{Ng}^{2,3}$, Eva Wai-Ying Tam ${ }^{1}$, Chung-Wah $\mathrm{Siu}^{4}$ and Katherine Fan ${ }^{1}$
}

\begin{abstract}
Background: For patients taking warfarin and undergoing pacemaker or implantable cardioverter-defibrillator surgery, clinical evidence and guidelines support continuation of warfarin therapy, as opposed to interruption of warfarin therapy with heparin bridging. Interruption of warfarin without post-operative bridging therapy may be a feasible alternative but data is sparse.

Methods: This is a single-arm observational study including adults who had interruption of warfarin therapy without post-operative bridging therapy for cardiac implantable electronic device (CIED) surgery performed between 2010 and 2019 in a tertiary referral hospital. The primary outcome was a composite of all-cause mortality, arterial or venous thromboembolic events. The secondary outcomes were clinically significant device-pocket hematoma and other procedural complications.

Results: Of the 411 patients analysed including 257 patients (62.5\%) who had mechanical heart valves, the primary outcome developed in 5 (1.2\%) patients within 30 days after surgery, including death in $3(0.7 \%)$ patients, transient ischemic attack in $1(0.2 \%)$ patient and non-CNS embolism in $1(0.2 \%)$ patient. Clinically significant hematomas occurred in 24 (5.8\%) patients, including 15 (3.7\%) requiring additional interruption of anti-coagulation and 6 (1.5\%) requiring clot evacuation. Other procedural complications and bleeding events were rare $(<1 \%)$.

Conclusions: Warfarin interruption without post-operative bridging therapy for CIED surgery was associated with low thromboembolic risks and acceptable bleeding risk. Randomized controlled trials are required to formulate an optimal approach to anti-coagulation management.
\end{abstract}

\footnotetext{
* Correspondence: drandrewkyng@gmail.com

${ }^{1}$ Cardiac Medical Unit, Grantham Hospital, 125 Wong Chuk Hang Road, Hong Kong SAR, China

Full list of author information is available at the end of the article
}

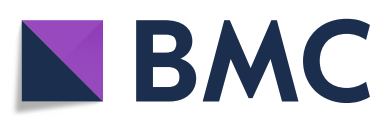

(- The Author(s). 2021 Open Access This article is licensed under a Creative Commons Attribution 4.0 International License, which permits use, sharing, adaptation, distribution and reproduction in any medium or format, as long as you give appropriate credit to the original author(s) and the source, provide a link to the Creative Commons licence, and indicate if changes were made. The images or other third party material in this article are included in the article's Creative Commons licence, unless indicated otherwise in a credit line to the material. If material is not included in the article's Creative Commons licence and your intended use is not permitted by statutory regulation or exceeds the permitted use, you will need to obtain permission directly from the copyright holder. To view a copy of this licence, visit http://creativecommons.org/licenses/by/4.0/ The Creative Commons Public Domain Dedication waiver (http://creativecommons.org/publicdomain/zero/1.0/) applies to the data made available in this article, unless otherwise stated in a credit line to the data. 


\section{Background}

Annually, an estimated 1.25 million pacemaker and 410, 000 implantable cardioverter defibrillator (ICD) operations are performed [1]. Between 14 and $37 \%$ of patients undergoing cardiac implantable electronic device (CIED) surgeries are on long-term anti-coagulation therapy, and the peri-procedural management of anti-coagulation presents a dilemma to physicians [2-5]. Interruption of anti-coagulation therapy can transiently increase the risks of thromboembolic events, but continuing anticoagulation therapy can increase the risk of surgical site hematoma formation. Importantly, there is an association between hematoma formation and subsequent device system infection. For example, patients with device infections were 20-fold and 8-fold more likely to have had postoperative hematomas in the REPLACE registry and the BRUISE CONTROL INFECTION study, respectively [6,7]. CIED infections frequently necessitate complete system removal, and are associated to increased morbidity, mortality and cost [8].

Randomized trials, most notably the BRUISE CONTROL (INFECTION) study, showed that continuation of warfarin was superior to the previous practice of interruption of warfarin therapy with heparin bridging [9-11]. However, a strategy of interruption of warfarin without heparin bridging have not been examined in these trials, and there is growing evidence that this may be a better peri-operative strategy. For example, in the BRIDGE randomized trial, patients with atrial fibrillation (AF) who had warfarin therapy interrupted for elective surgeries (not including CIED surgeries) without heparin bridging benefited from fewer bleeding complications with no excessive thromboembolic risks [12].

We sought to examine the risks of thromboembolic events and clinically significant device pocket hematoma with a strategy of warfarin interruption without postoperative heparin bridging in moderate or high risk patients undergoing CIED surgeries.

\section{Methods}

\section{Study population and design}

Data from consecutive patients who were taking chronic warfarin therapy and underwent CIED surgery between January 1, 2010 and December 31, 2019 at Grantham Hospital, Hong Kong were reviewed. The study was approved by the Institutional Review Board of the University of Hong Kong / Hospital Authority, and a waiver of informed consent was granted.

We included all adult patients (18years of age or older) who were on chronic warfarin therapy, underwent CIED surgeries (including pacemaker implantations, cardiac resynchronization therapy, ICD implantations, and generator replacements) and had interruption of warfarin therapy without any post-operative bridging therapy with heparin or any other anti-coagulant. Preoperative heparin bridging was allowed until $12 \mathrm{~h}$ before surgery. We excluded patients who underwent lead extractions or leadless pacemaker implantation within the same index procedure, had a warfarin interruption period of less than $24 \mathrm{~h}$, or lost to follow-up within 6 months after the index procedure.

\section{Definitions of exposure and outcome variables}

The primary outcome was all-cause mortality, and a composite of perioperative thromboembolic events including transient ischemic attack (TIA), ischemic stroke, peripheral artery and venous thromboembolism, within 30 days after CIED surgery.

The secondary outcome was a composite of clinically significant device-pocket hematoma: defined as any surgical site hematoma requiring repeated surgery and/or blood transfusion, or resulting in prolongation of hospitalization, or requiring additional interruption of oral anticoagulation therapy. Prolongation of hospitalization was defined as extended hospitalization for at least $24 \mathrm{~h}$ after the index surgical procedure or any re-hospitalization, primarily for management of hematoma. Additional interruption of anticoagulation therapy was defined as reversal or intentional delayed resumption of warfarin therapy for at least $24 \mathrm{~h}$, primarily due to surgical site hematoma. All events were confirmed by chart review by two independent investigators.

The total warfarin interruption period was defined as the duration from $12 \mathrm{~h}$ after the last dose of unfractionated or low molecular weight heparin, until the first international normalized ratio (INR) of $>1.8$, or when the INR is no longer tested on a daily basis, as it reflects attainment of target INR values.

\section{Routine procedural protocol}

As per our routine protocol for CIED surgeries, warfarin was discontinued 3-4 days prior to and resumed 0-1 day after the procedure. Pre-operative low molecular weight heparin (LMWH) was given to patients with high thrombotic risks (e.g., those with mechanical heart valves, mitral stenosis of at least moderate severity, or $\mathrm{CHAD}_{2} \mathrm{~S}_{2}$-VASc score $\geq 2$ ) when the INR fell below 1.82.0, and continued until $12 \mathrm{~h}$ before the procedure. Postoperative LMWH was not given. Aspirin and P2Y12 inhibitors were continued if indicated. All patients received intravenous prophylactic antibiotics. A pressure dressing was routinely applied to the surgical wound postoperatively and left in place overnight.

\section{Statistical analysis}

Data are presented as mean with standard deviation or median with interquartile range as appropriate. Descriptive analysis of baseline characteristics, procedural 
details, primary and secondary outcomes were reported for the entire cohort and stratified by presence of any mechanical heart valves. In the exploratory analysis, we used a self-controlled case-series design to explore the association between CIED surgery and thromboembolic events, by defining the "risk interval" as the first 30 days after CIED surgery and the "control interval" as 12 months before and 11 months after the risk interval [13]. Data management and statistical analyses were performed in Stata software (StataCorp/ MP version 16).

\section{Results}

\section{Patients and characteristics}

Between January 2010 to December 2019, a total of 430 patients were considered for inclusion: 19 (4.4\%) were excluded due to any of the exclusion criteria (Fig. 1). No patients were lost to follow-up. The baseline characteristics of the patients are shown in Tables $1 \& 2$. Of the 411 patients included in analysis, 257 (62.5\%) had at least one mechanical prosthetic valve. Among the patients without mechanical prosthetic valve, 132 (85.7\%) were taking warfarin because of atrial fibrillation or atrial flutter. Procedural details and peri-operative anticoagulation management are shown in Table 3. The mean INR on the day of surgery was $1.44 \pm 0.22$ and the mean duration without any therapeutic anti-coagulation was $4.04 \pm 2.04$ days. Pre-operative heparin bridging was given in $57.2 \%$ of patients.

\section{Primary and secondary outcomes}

Of the 411 patients analysed, the primary composite outcome occurred in $5(1.2 \%)$ patients within 30 days after surgery, including $3(0.7 \%)$ deaths - one patient died of subarachnoid hemorrhage and two patients died of sudden cardiac arrest, $1(0.2 \%)$ transient ischemic attack and $1(0.2 \%)$ non-central nervous system (CNS) embolism. Clinically significant hematomas occurred in 24 (5.8\%) patients, including 15 (3.7\%) who required additional interruption of anti-coagulation and $6(1.5 \%)$ who required clot evacuation. Other thromboembolic and bleeding events were rare. The study outcomes are detailed in Tables 4 and 5.

The primary endpoint occurred at similar frequencies in the mechanical valve compared with the no mechanical valve group (unadjusted risk ratio 2.40 [95\% confidence interval, $0.27-21.20] ; P=0.66$ ).

\section{Exploratory analysis}

We identified 22 (5.4\%) patients who had arterial or venous thromboembolic events during the control interval of 12 months before and between 1 to 12 months after CIED surgery. The risks of thromboembolic events were not significantly different during the risk interval and the control interval (risk ratio 3.08 [95\% confidence interval 0.92-10.2]; $P=0.054$ ).

\section{Discussion}

In this cohort of patients on chronic warfarin therapy undergoing CIED surgery with moderate to high

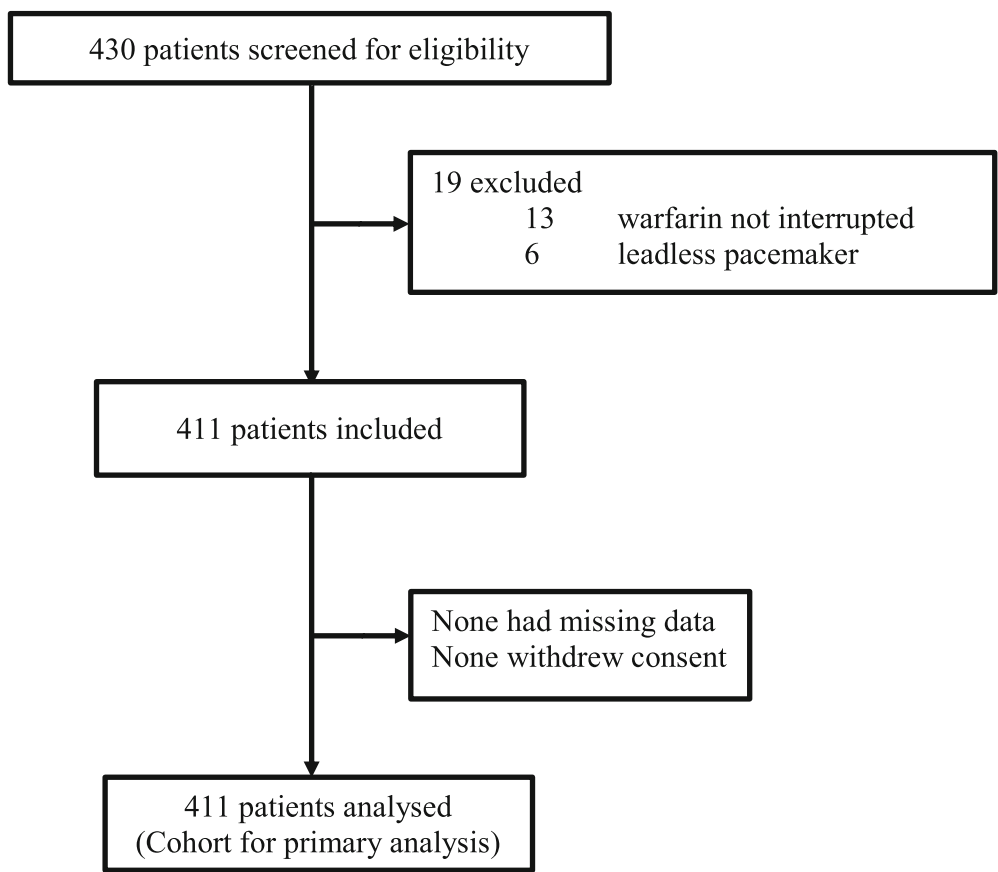

Fig. 1 Study profile 
Table 1 Baseline characteristics of patients, stratified by presence of mechanical valves

\begin{tabular}{|c|c|c|c|c|c|c|}
\hline \multirow[b]{2}{*}{ Age - yr \pm S.D. } & \multicolumn{2}{|c|}{$\begin{array}{l}\text { All patients } \\
N=411\end{array}$} & \multicolumn{2}{|c|}{$\begin{array}{l}\text { Mechanical valve } \\
N=257\end{array}$} & \multicolumn{2}{|c|}{$\begin{array}{l}\text { No mechanical valve } \\
N=154\end{array}$} \\
\hline & 66.67 & \pm 11.92 & 65.56 & \pm 10.04 & 65.85 & \pm 14.56 \\
\hline Age > 65 - no. (\%) & 208 & $50.6 \%$ & 129 & $50.2 \%$ & 79 & $51.3 \%$ \\
\hline Male sex - no. (\%) & 178 & $43.3 \%$ & 90 & $35.0 \%$ & 88 & $57.1 \%$ \\
\hline \multicolumn{7}{|l|}{ Medical history - no. (\%) } \\
\hline Rheumatic heart disease & 251 & $61.1 \%$ & 224 & $87.2 \%$ & 27 & $17.5 \%$ \\
\hline Mitral stenosis (native valve) & 13 & $3.2 \%$ & 0 & $0.0 \%$ & 13 & $8.4 \%$ \\
\hline Tricuspid regurgitation (at least moderate) & $156 / 277$ & $56.3 \%$ & $111 / 186$ & $59.7 \%$ & $45 / 91$ & $49.5 \%$ \\
\hline Prior transient ischemic attack & 21 & $5.1 \%$ & 16 & $6.2 \%$ & 5 & $3.3 \%$ \\
\hline Prior ischemic stroke & 54 & $13.1 \%$ & 32 & $12.5 \%$ & 22 & $14.3 \%$ \\
\hline Prior non-CNS embolic event & 3 & $0.7 \%$ & 1 & $0.4 \%$ & 2 & $1.3 \%$ \\
\hline Hypertension & 159 & $38.7 \%$ & 89 & $34.6 \%$ & 70 & $45.5 \%$ \\
\hline Diabetes mellitus & 100 & $24.3 \%$ & 58 & $22.6 \%$ & 42 & $27.3 \%$ \\
\hline Chronic kidney disease (eGFR<30 ml/m²) & 68 & $16.5 \%$ & 35 & $13.6 \%$ & 33 & $21.4 \%$ \\
\hline Cardiomyopathy & 112 & $27.3 \%$ & 37 & $14.4 \%$ & 75 & $48.7 \%$ \\
\hline Coronary artery disease & 61 & $14.8 \%$ & 19 & $7.4 \%$ & 42 & $27.3 \%$ \\
\hline Percutaneous coronary intervention & 30 & $7.3 \%$ & 6 & $2.2 \%$ & 24 & $15.6 \%$ \\
\hline Coronary-artery bypass surgery & 15 & $3.7 \%$ & 7 & $2.7 \%$ & 8 & $5.2 \%$ \\
\hline Left ventricular ejection fraction $<50 \%$ & 147 & $35.8 \%$ & 74 & $28.8 \%$ & 73 & $47.4 \%$ \\
\hline Left ventricular ejection fraction - percentage point \pm S.D & 50.75 & \pm 17.66 & 53.74 & \pm 15.92 & 45.75 & \pm 19.27 \\
\hline
\end{tabular}

Abbreviation: S.D. standard deviation

Table 2 Baseline characteristics of patients, stratified by presence of mechanical valves

\begin{tabular}{|c|c|c|c|c|c|c|}
\hline Indication for warfarin therapy - no. (\%) & \multicolumn{2}{|c|}{$\begin{array}{l}\text { All patients } \\
N=411\end{array}$} & \multicolumn{2}{|c|}{$\begin{array}{l}\text { Mechanical valve } \\
N=257\end{array}$} & \multicolumn{2}{|c|}{$\begin{array}{l}\text { No mechanical valve } \\
N=154\end{array}$} \\
\hline Mechanical heart valve replacement (any) & 257 & $62.5 \%$ & 257 & $100.0 \%$ & & \\
\hline Mechanical mitral valve replacement & 212 & $51.3 \%$ & 212 & $82.5 \%$ & & \\
\hline Mechanical aortic valve replacement & 121 & $29.0 \%$ & 121 & $47.1 \%$ & & \\
\hline Mitral stenosis (native valve) & 13 & $3.2 \%$ & & & 13 & $8.4 \%$ \\
\hline Atrial fibrillation or atrial flutter & 318 & $77.4 \%$ & 186 & $72.4 \%$ & 132 & $85.7 \%$ \\
\hline CHAD2S2-VASC (for non-valvular AF; $N=119$ ) - mean \pm S.D. & & & & & 3.34 & \pm 1.93 \\
\hline CHAD2S2-VASC $\geq 2$ (for non-valvular AF; $N=119$ ) & & & & & 96 & $80.7 \%$ \\
\hline Deep vein thrombosis or pulmonary embolism & 4 & $1.0 \%$ & 0 & $0.0 \%$ & 4 & $2.6 \%$ \\
\hline Intracardiac thrombus & 14 & $3.4 \%$ & 0 & $0.0 \%$ & 14 & $9.1 \%$ \\
\hline \multicolumn{7}{|l|}{ Medications - no. (\%) } \\
\hline Any anti-platelet therapy & 69 & $16.8 \%$ & 20 & $7.8 \%$ & 49 & $31.8 \%$ \\
\hline Aspirin & 68 & $16.6 \%$ & 20 & $7.8 \%$ & 48 & $31.2 \%$ \\
\hline P2Y12 inhibitor & 5 & $1.2 \%$ & 1 & $0.4 \%$ & 4 & $2.6 \%$ \\
\hline Statin & 153 & $37.2 \%$ & 78 & $30.4 \%$ & 75 & $48.7 \%$ \\
\hline ACE inhibitor or ARB & 215 & $52.3 \%$ & 117 & $45.5 \%$ & 98 & $63.6 \%$ \\
\hline Beta-blocker & 220 & $53.5 \%$ & 118 & $45.9 \%$ & 102 & $66.2 \%$ \\
\hline Diuretics & 312 & $75.9 \%$ & 196 & $76.3 \%$ & 116 & $75.3 \%$ \\
\hline Pre-operative low molecular weight heparin & 235 & $57.2 \%$ & 181 & $70.4 \%$ & 54 & $35.0 \%$ \\
\hline
\end{tabular}


Table 3 Baseline and intraoperative characteristics of patients

\begin{tabular}{|c|c|c|c|c|c|c|}
\hline CIED procedure - no. (\%) & \multicolumn{2}{|c|}{$\begin{array}{l}\text { All patients } \\
N=411\end{array}$} & \multicolumn{2}{|c|}{$\begin{array}{l}\text { Mechanical valve } \\
N=257\end{array}$} & \multicolumn{2}{|c|}{$\begin{array}{l}\text { No mechanical valve } \\
N=154\end{array}$} \\
\hline \multicolumn{7}{|l|}{ New implant } \\
\hline \multicolumn{7}{|l|}{ Pacemaker } \\
\hline Single or dual chamber & 131 & $31.9 \%$ & 81 & $31.5 \%$ & 50 & $32.5 \%$ \\
\hline Cardiac resynchronization therapy & 14 & $3.4 \%$ & 9 & $3.5 \%$ & 5 & $3.3 \%$ \\
\hline \multicolumn{7}{|l|}{ Implantable cardioverter-defibrillator } \\
\hline Single or dual chamber & 21 & $5.1 \%$ & 6 & $2.3 \%$ & 15 & $9.7 \%$ \\
\hline Cardiac resynchronization therapy & 27 & $6.6 \%$ & 9 & $3.5 \%$ & 18 & $11.7 \%$ \\
\hline \multicolumn{7}{|l|}{ Device replacement or revision } \\
\hline Pulse-generator change only & 191 & $46.5 \%$ & 129 & $50.2 \%$ & 6 & $40.3 \%$ \\
\hline Pulse-generator change with additional procedure & 27 & $6.6 \%$ & 23 & $9.0 \%$ & 4 & $2.6 \%$ \\
\hline INR on day of surgery - mean \pm S.D. & 1.44 & \pm 0.22 & 1.44 & \pm 0.21 & 1.43 & \pm 0.24 \\
\hline \multicolumn{7}{|l|}{ Warfarin resumption after surgery -days } \\
\hline Mean \pm S.D. & 0.46 & \pm 1.01 & 0.23 & \pm 0.51 & 0.84 & \pm 1.45 \\
\hline Median, IQR & 0 & $0-1$ & 0 & $0-0$ & 0 & $0-1$ \\
\hline \multicolumn{7}{|l|}{ Anti-coagulation interruption period - days } \\
\hline Mean \pm S.D. & 4.04 & \pm 2.04 & 3.91 & \pm 1.71 & 4.27 & \pm 2.47 \\
\hline Median (IQR) & 3 & $3-5$ & 3 & $3-5$ & 4 & $3-5$ \\
\hline
\end{tabular}

Abbreviations: CIED cardiac implantable electronic device, S.D. standard deviation, IQR interquartile range

thromboembolic risks, a strategy of warfarin interruption without post-operative bridging therapy were found to have a relatively low risk of all-cause death or thromboembolism (1.2\%) and an acceptable risk of device-pocket hematoma (5.8\%). Importantly, we included more than $60 \%$ patients with mechanical prosthetic valves and showed that the rates of thromboembolism was comparable with patients without mechanical valves.

There is increasing evidence supporting continued warfarin therapy for CIED surgeries. In the BRUISE CONTROL trial including 668 patients with AF, continued warfarin therapy was superior with respect to risks of major bleeding and non-inferior to heparin bridging with respect to arterial thrombo-embolism [9]. This has led to a shift in European and American guidelines towards favoring continued warfarin therapy over interruption with bridging therapy for CIED surgeries [14-16]. However, there is limited published data on the efficacy and safety of the strategy of warfarin interruption and no post-operative bridging therapy used in our cohort.

According to a European survey, 9.4\% patients undergoing CIED surgeries had warfarin interrupted for more

Table 4 Primary outcomes at 30 days after surgery

\begin{tabular}{|c|c|c|c|c|c|c|}
\hline Primary Outcome - no. (\%) & \multicolumn{2}{|c|}{$\begin{array}{l}\text { All patients } \\
N=411\end{array}$} & \multicolumn{2}{|c|}{$\begin{array}{l}\text { Mechanical valve } \\
N=257\end{array}$} & \multicolumn{2}{|c|}{$\begin{array}{l}\text { No mechanical valve } \\
N=154\end{array}$} \\
\hline Death or any thromboembolic events & 5 & $1.2 \%$ & 4 & $1.6 \%$ & 1 & $0.6 \%$ \\
\hline \multicolumn{7}{|l|}{ Components of primary outcome } \\
\hline Death from any cause & 3 & $0.7 \%$ & 2 & $0.8 \%$ & 1 & $0.6 \%$ \\
\hline Transient ischemic attack & 1 & $0.2 \%$ & 1 & $0.4 \%$ & 0 & $0.0 \%$ \\
\hline Ischemic stroke & 0 & $0.0 \%$ & 0 & $0.0 \%$ & 0 & $0.0 \%$ \\
\hline Non-CNS embolism & 1 & $0.2 \%$ & 1 & $0.4 \%$ & 0 & $0.0 \%$ \\
\hline Deep vein thrombosis & 0 & $0.0 \%$ & 0 & $0.0 \%$ & 0 & $0.0 \%$ \\
\hline Pulmonary embolism & 0 & $0.0 \%$ & 0 & $0.0 \%$ & 0 & $0.0 \%$ \\
\hline Valve thrombosis & 0 & $0.0 \%$ & 0 & $0.0 \%$ & 0 & $0.0 \%$ \\
\hline
\end{tabular}


Table 5 Secondary outcomes at 30 days after surgery

\begin{tabular}{|c|c|c|c|c|c|c|}
\hline \multirow{2}{*}{ Secondary outcomes - no. (\%) } & \multicolumn{2}{|c|}{$\begin{array}{l}\text { All patients } \\
N=411\end{array}$} & \multicolumn{2}{|c|}{$\begin{array}{l}\text { Mechanical valve } \\
N=257\end{array}$} & \multicolumn{2}{|c|}{$\begin{array}{l}\text { No mechanical valve } \\
N=154\end{array}$} \\
\hline & & & & & & \\
\hline Clinically significant hematoma & 24 & $5.8 \%$ & 18 & $7.0 \%$ & 6 & $3.9 \%$ \\
\hline Hematoma prolonging hospitalization & 24 & $5.8 \%$ & 18 & $7.0 \%$ & 6 & $3.9 \%$ \\
\hline Hematoma requiring additional interruption of anti-coagulation & 15 & $3.7 \%$ & 9 & $3.5 \%$ & 6 & $3.9 \%$ \\
\hline Hematoma requiring evacuation & 6 & $1.5 \%$ & 4 & $1.6 \%$ & 2 & $1.3 \%$ \\
\hline Pneumothorax & 0 & $0.0 \%$ & 0 & $0.0 \%$ & 0 & $0.0 \%$ \\
\hline Hemothorax & 0 & $0.0 \%$ & 0 & $0.0 \%$ & 0 & $0.0 \%$ \\
\hline Cardiac tamponade & 0 & $0.0 \%$ & 0 & $0.0 \%$ & 0 & $0.0 \%$ \\
\hline Lead dislodgement & 4 & $1.0 \%$ & 3 & $1.2 \%$ & 1 & $0.7 \%$ \\
\hline Infection related to device system & 4 & $1.0 \%$ & 3 & $1.2 \%$ & 1 & $0.7 \%$ \\
\hline Myocardial infarction & 0 & $0.0 \%$ & 0 & $0.0 \%$ & 0 & $0.0 \%$ \\
\hline Major bleeding unrelated to CIED & 2 & $0.5 \%$ & 2 & $0.8 \%$ & 0 & $0.0 \%$ \\
\hline
\end{tabular}

Abbreviation: CIED cardiac implantable electronic device

than $24 \mathrm{~h}$ without bridging therapy, amid a lack of general consensus or clinical evidence [17]. Indirect clinical evidence supporting this practice stems from the setting of elective non-cardiac procedures, where randomized trials (including the BRIDGE trial) and cohort studies showed that warfarin interruption without bridging therapy was superior to with bridging therapy, with lower bleeding risks and no excess risks of thromboembolism $[12,18]$. . Moreover, in patients undergoing CIED implantations, post-operative LMWH and higher INR on day of CIED implantations were independent predictors of device-related hematoma in a case-control study [19]. Therefore, a strategy of warfarin interruption without post-operative bridging therapy has theoretical advantage in simultaneously addressing both risk factors. This naturally raises concern about thromboembolic risks during the period of warfarin interruption. The rationale of heparin bridging was to leverage the short half-life of LMWH $(3-5 \mathrm{~h})$ to maximize protection against thromboembolism during the pre-operative period, given the time period for INR normalization after warfarin interruption is widely variable $[20,21]$.

To our knowledge, our study is the largest cohort reporting the safety and efficacy in patients who had warfarin interruption for CIED surgeries without postoperative heparin bridging. Ahmed et al. reported data including 114 patients who had warfarin interruption for CIED implantations, and found significantly higher risks of TIA [22]. However pre-operative bridging therapy was not given and none of the patients had irreversible thromboembolic events. Another nation-wide registry included 150 patients with AF who had warfarin interruption for CIED implantations without bridging therapy, and both bleeding and thromboembolic events were very low $(<1 \%)$ [23]. A prematurely terminated trial randomized 171 patients and showed that events were similarly infrequent for reduced-dose warfarin vs warfarin interruption with LMWH bridging, including zero thromboembolic events [24]. Although observational in nature, our data suggests that the strategy under study conferred relatively low thromboembolic risks, which were not significantly higher than the study population's baseline risks. These results should be considered hypothesis-generating for future randomized studies.

The risks of all-cause mortality and non-fatal thromboembolic event in our patients were 0.7 and $0.4 \%$ respectively, which were comparable with both arms in the BRUISE CONTROL trial ( 0 and $0 \%$ respectively for the heparin bridging arm, and 1.2 and $0.6 \%$ respectively for the continued warfarin arm) [9]. The risks of clinically significant hematoma in our patients were $5.8 \%$, comparable with the reported $4.6 \%$ in a meta-analysis of 5978 patients receiving CIED with various combinations of anti-coagulant and/or anti-platelet therapy [25]. Specifically, the risks of bleeding complication in our cohort were much lower than the heparin bridging arm (16\%) but numerically higher than the continued warfarin arm (3.5\%) in the BRUISE CONTROL trial [9]. This could be attributed to the high portion of patients with valvular heart disease including more than half with at least moderate tricuspid regurgitation. Tricuspid regurgitation is associated with increased venous pressures and could adversely affect wound hemostasis. In addition, the main subcomponent of bleeding events in our patients was prolonged hospitalization secondary to management of hematoma. This endpoint could be affected by local discharge policies, as the pressure to discharge early from hospital is small in a non-insurance funded system. The other two subcomponents of bleeding events, hematoma requiring interruption of anti-coagulation (3.7\%) and 
hematoma requiring evacuation (1.5\%), were similar to the continued warfarin arm (3.2 and $0.6 \%$ respectively) and much lower than the heparin bridging arm (14.2 and $2.7 \%$ respectively) in the BRUISE CONTROL trial [9]. Nonetheless, comparisons across different patient cohorts are inherently limited, and a randomized trial is needed to compare the two strategies.

Importantly, our patients represented a cohort with moderate to high thromboembolic risks. We included $257(62.5 \%)$ patients with mechanical prosthetic valves and a strategy of warfarin interruption without heparin bridging has never been reported in this population. The primary endpoint occurred at similar frequencies for the mechanical valve and no mechanical valve groups, providing preliminary findings that this anti-coagulation strategy in patients with mechanical valves may be considered.

The strengths of the present study include complete follow-up of all patients, large cohort size compared with previous studies that evaluated no bridging therapy, and inclusion of a sizeable proportion of patients with mechanical prosthetic valves whose outcomes with the current strategy have never been reported. The main limitation is the lack of a comparison group of either continued warfarin therapy or interruption of warfarin with bridging therapy. However, the findings arising from this study should serve to inform future randomized non-inferiority studies comparing our strategy of warfarin interruption without post-operative bridging therapy versus continued warfarin therapy.

\section{Conclusion}

Warfarin interruption without post-operative bridging therapy for CIED surgery was associated with relatively low thromboembolic risks and bleeding risks comparable to other cohorts. This approach to anti-coagulation management deserves further direct comparison with continued warfarin therapy in randomized controlled trials.

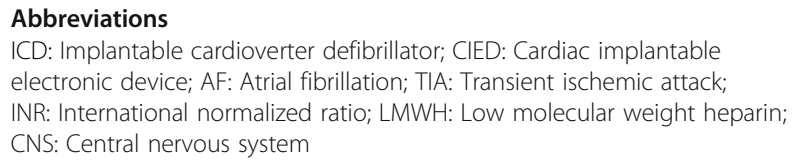
electronic device; AF: Atrial fibrillation; TIA: Transient ischemic attack; INR: International normalized ratio; LMWH: Low molecular weight heparin; CNS: Central nervous system

\section{Acknowledgements}

Not applicable.

Authors' information (optional)

As stated above.

\section{Authors' contributions}

AKN, CWS, KF were responsible for the conception and design of the study. AKN analyzed the data collected by EWT. AKN interpreted the data. AKN and PYN drafted the manuscript. All authors revised and approved the final manuscript, and are accountable for the accuracy and integrity of the work.
Funding

Nil.

Availability of data and materials

Not applicable.

\section{Declarations}

Ethics approval and consent to participate

The study was approved by the Institutional Review Board of the University of Hong Kong / Hospital Authority, and a waiver of informed consent was granted.

Consent for publication

All authors consent to publication.

\section{Competing interests}

Nil.

\section{Author details}

${ }^{1}$ Cardiac Medical Unit, Grantham Hospital, 125 Wong Chuk Hang Road, Hong Kong SAR, China. ${ }^{2}$ Department of Adult Intensive Care, Queen Mary Hospital, 102 Pokfulam Road, Hong Kong SAR, China. ${ }^{3}$ Division of Respiratory and Critical Care Medicine, Department of Medicine, Li Ka Shing Faculty of Medicine, The University of Hong Kong, Hong Kong SAR, China. ${ }^{4}$ Department of Medicine, Queen Mary Hospital, The University of Hong Kong, Hong Kong SAR, China.

Received: 11 February 2021 Accepted: 13 April 2021

Published online: 29 April 2021

References

1. Mond HG, Proclemer A. The 11th world survey of cardiac pacing and implantable cardioverter-defibrillators: calendar year 2009--a world Society of Arrhythmia's project. Pacing Clin Electrophysiol. 2011;34(8):1013-27. https://doi.org/10.1111/j.1540-8159.2011.03150.x.

2. Bardy GH, Lee $\mathrm{KL}$, Mark DB, Poole JE, Packer DL, Boineau R, et al. Amiodarone or an implantable cardioverter-defibrillator for congestive heart failure. N Engl J Med. 2005;352(3):225-37. https://doi.org/10.1056/NEJMoa 043399.

3. Greenspon AJ, Hart RG, Dawson D, Hellkamp AS, Silver M, Flaker GC, et al. Predictors of stroke in patients paced for sick sinus syndrome. J Am Coll Cardiol. 2004;43(9):1617-22. https://doi.org/10.1016/j.jacc.2003.09.067.

4. Nielsen JC, Thomsen PE, Hojberg S, et al. A comparison of single-lead atrial pacing with dual-chamber pacing in sick sinus syndrome. Eur Heart J. 2011; 32(6):686-96. https://doi.org/10.1093/eurheartj/ehr022.

5. Tang AS, Wells GA, Talajic M, et al. Cardiac-resynchronization therapy for mild-to-moderate heart failure. N Engl J Med. 2010;363(25):2385-95. https:// doi.org/10.1056/NEJMoa1009540.

6. Uslan DZ, Gleva MJ, Warren DK, et al. Cardiovascular implantable electronic device replacement infections and prevention: results from the REPLACE registry. Pacing Clin Electrophysiol. 2012;35(1):81-7. https://doi.org/10.1111/ j.1540-8159.2011.03257.x.

7. Essebag V, Verma A, Healey JS, Krahn AD, Kalfon E, Coutu B, et al. Clinically significant pocket hematoma increases long-term risk of device infection: BRUISE CONTROL INFECTION study. J Am Coll Cardiol. 2016;67(11):1300-8. https://doi.org/10.1016/j.jacc.2016.01.009.

8. Sohail MR, Henrikson CA, Braid-Forbes MJ, Forbes KF, Lerner DJ. Mortality and cost associated with cardiovascular implantable electronic device infections. Arch Intern Med. 2011;171(20):1821-8. https://doi.org/10.1001/a rchinternmed.2011.441.

9. Birnie DH, Healey JS, Wells GA, Verma A, Tang AS, Krahn AD, et al. Pacemaker or defibrillator surgery without interruption of anticoagulation. N Engl J Med. 2013;368(22):2084-93. https://doi.org/10.1056/NEJMoa1302946.

10. Sant'anna RT, Leiria TL, Nascimento T, et al. Meta-analysis of continuous oral anticoagulants versus heparin bridging in patients undergoing CIED surgery: reappraisal after the BRUISE study. Pacing Clin Electrophysiol. 2015; 38(4):417-23. https://doi.org/10.1111/pace.12557.

11. Yang $X$, Wang $Z$, Zhang $Y$, Yin $X$, Hou $Y$. The safety and efficacy of antithrombotic therapy in patients undergoing cardiac rhythm device 
implantation: a meta-analysis. Europace. 2015;17(7):1076-84. https://doi. org/10.1093/europace/euu369.

12. Douketis JD, Spyropoulos AC, Kaatz S, Becker RC, Caprini JA, Dunn AS, et al. Perioperative bridging anticoagulation in patients with atrial fibrillation. $\mathrm{N}$ Engl J Med. 2015;373(9):823-33. https://doi.org/10.1056/NEJMoa1501035.

13. Kwong JC, Schwartz KL, Campitelli MA, Chung H, Crowcroft NS, Karnauchow T, et al. Acute myocardial infarction after laboratory-confirmed influenza infection. N Engl J Med. 2018;378(4):345-53. https://doi.org/10.1056/ NEJMoa1702090.

14. Kirchhof P, Benussi S, Kotecha D, Ahlsson A, Atar D, Casadei B, et al. 2016 ESC guidelines for the management of atrial fibrillation developed in collaboration with EACTS. Eur Heart J. 2016;37(38):2893-962. https://doi. org/10.1093/eurhearti/ehw210.

15. Sticherling C, Marin F, Birnie D, Boriani G, Calkins H, Dan GA, et al. Antithrombotic management in patients undergoing electrophysiological procedures: a European heart rhythm association (EHRA) position document endorsed by the ESC working group thrombosis, Heart Rhythm Society (HRS), and Asia Pacific Heart Rhythm Society (APHRS). Europace. 2015;17(8): 1197-214. https://doi.org/10.1093/europace/euv190.

16. Doherty JU, Gluckman TJ, Hucker WJ, Januzzi JL Jr, Ortel TL, Saxonhouse SJ, et al. 2017 ACC expert consensus decision pathway for Periprocedural Management of Anticoagulation in patients with Nonvalvular atrial fibrillation: a report of the American College of Cardiology Clinical Expert Consensus Document Task Force. J Am Coll Cardiol. 2017;69(7):871-98. https://doi.org/10.1016/j.jacc.2016.11.024.

17. Deharo JC, Sciaraffia E, Leclerca C, Amara W, Doering M, Bongiorni MG, et al. Perioperative management of antithrombotic treatment during implantation or revision of cardiac implantable electronic devices: the European snapshot survey on procedural routines for electronic device implantation (ESS-PREDI). Europace. 2016;18(5):778-84. https://doi.org/10.1 093/europace/euw127.

18. Siegal D, Yudin J, Kaatz S, Douketis JD, Lim W, Spyropoulos AC. Periprocedural heparin bridging in patients receiving vitamin $\mathrm{K}$ antagonists: systematic review and meta-analysis of bleeding and thromboembolic rates. Circulation. 2012;126(13):1630-9. https://doi.org/10.1161/CIRCULATIONA HA.112.105221.

19. Robinson M, Healey JS, Eikelboom J, et al. Postoperative low-molecularweight heparin bridging is associated with an increase in wound hematoma following surgery for pacemakers and implantable defibrillators. Pacing Clin Electrophysiol. 2009;32(3):378-82. https://doi.org/10.1111/j.15408159.2008.02247.x

20. Douketis JD, Spyropoulos AC, Spencer FA, Mayr M, Jaffer AK, Eckman MH, et al. Perioperative management of antithrombotic therapy: antithrombotic therapy and prevention of thrombosis, 9th ed: American College of Chest Physicians Evidence-Based Clinical Practice Guidelines. Chest. 2012;141(2): e326S-e50S. https://doi.org/10.1378/chest.11-2298.

21. White RH, McKittrick T, Hutchinson R, Twitchell J. Temporary discontinuation of warfarin therapy: changes in the international normalized ratio. Ann Intern Med. 1995;122(1):40-2. https://doi.org/10.7326/0003-4819-122-1-1 99501010-00006

22. Ahmed I, Gertner E, Nelson WB, House CM, Dahiya R, Anderson CP, et al. Continuing warfarin therapy is superior to interrupting warfarin with or without bridging anticoagulation therapy in patients undergoing pacemaker and defibrillator implantation. Heart Rhythm. 2010;7(6):745-9. https://doi.org/10.1016/j.hrthm.2010.02.018.

23. Black-Maier E, Kim S, Steinberg BA, Fonarow GC, Freeman JV, Kowey PR, et al. Oral anticoagulation management in patients with atrial fibrillation undergoing cardiac implantable electronic device implantation. Clin Cardiol. 2017;40(9):746-51. https://doi.org/10.1002/clc.22726.

24. Schulman S, Healey JS, Douketis JD, Delaney J, Morillo CA. Reduced-dose warfarin or interrupted warfarin with heparin bridging for pacemaker or defibrillator implantation: a randomized trial. Thromb Res. 2014;134(4):814-8. https://doi.org/10.1016/j.thromres.2014.07.028.

25. Bernard ML, Shotwell M, Nietert PJ, Gold MR. Meta-analysis of bleeding complications associated with cardiac rhythm device implantation. Circ Arrhythm Electrophysiol. 2012;5(3):468-74. https://doi.org/10.1161/ CIRCEP.111.969105

\section{Publisher's Note}

Springer Nature remains neutral with regard to jurisdictional claims in published maps and institutional affiliations.

Ready to submit your research? Choose BMC and benefit from:

- fast, convenient online submission

- thorough peer review by experienced researchers in your field

- rapid publication on acceptance

- support for research data, including large and complex data types

- gold Open Access which fosters wider collaboration and increased citations

- maximum visibility for your research: over $100 \mathrm{M}$ website views per year

At BMC, research is always in progress.

Learn more biomedcentral.com/submissions 